\title{
Suggestions to close the gap in nursing education: Nursing students' perspectives
}

\author{
Ahmad Rajeh Saifan ${ }^{1 *}$, Haneen Abu Safieh ${ }^{2}$, Ruba Milbes ${ }^{2}$, Rawan Shibly ${ }^{2}$ \\ ${ }^{1}$ Associate Professor, School of Nursing, Applied Science Private University, Amman, Jordan \\ ${ }^{2}$ School of Nursing, Applied Science Private University, Amman, Jordan \\ *Corresponding author E-mail: a_saifan@asu.edu.jo
}

\begin{abstract}
Background: The nursing profession is composed of two main parts: the theoretical part, which reflects the knowledge that is received in the classroom; and the practical part, which focuses on improving students' skills in the clinical area. The literature shows that there is a disconnect between these two parts.

Objectives: This study aimed to identify suggestions and interventions to explore students' perceptions about the theory-practice gap in nursing education.

Methods: An explorative qualitative design with individual, face-to-face, semi-structured interviews with 30 nursing students (in the second, third and fourth year of their BSc program) who took at least two clinical courses.

Results: The students raised several ideas and suggestions to close the theory-practice gap in nursing education grouped under five major themes: open channels between theory and practice teachers; students need to be supported more; increasing competency of clinical instructors; using different methods of education; and preparing and improving the clinical laboratories.

Conclusion: The qualitative design used in this study provided deep and rich novel data about the theory-practice gaps in nursing education in Jordan. This subject was broached for the first time in Jordan. The information from this study could be useful for undergraduate students, nursing schools, nursing teachers and other healthcare stakeholders in Jordan.
\end{abstract}

Keywords: Theory-Practice Gap; Nursing; Education; Jordan.

\section{Introduction}

The nursing profession is composed of two main parts; the theoretical part, which reflects the knowledge that is received in the classroom; and the practical part, which focuses on improving skills in the clinical area. Both of these are part of continuous lifelong learning that is expected of the modern nursing professional to improve nursing and thus healthcare systems worldwide. The theory part should provide the basis for understanding the reality of nursing (Dale, 1994; Nabolsi et al., 2012). In classrooms, nursing students are taught the theoretical basis for all procedures, diseases, interpersonal skills and requirements to be a nurse (Landers, 2000). On the other side, the practical part provides nursing students with a mechanism to extend classroom learning into the nursing practice environments (McKenna \& Wellard, 2009). Several authors have suggested that education in the clinical environment participates in shaping the professional development of student nurses (Fitzpatrick While, \& Roberts, 1996; Budgen \& Garmoth, 2008).

The literature shows that there is a gap between the theory and practice components of nursing education (Allan, 2011; Chan, 2013; Landers, 2000; McKenna \& Wellard, 2009). Several reasons for this gap were reported in the literature, such as using abstract meanings to explain some procedures in the clinical environment (Chan, 2013). The subjectivity in defining nursing terms and theories and giving different meanings to these terms formed challenges for nursing students (Upton, 1999). Students found it difficult to link what they learned in the classroom with the facts they faced in the complex clinical environment. The development in nursing education and the move toward higher education also increased the gap (Fairbrother \& Ford, 1998; McKenna \& Wellard 2009). Other reasons were expected to increase this gap, such as the complexity and the continuous change in the clinical environment (Nabolsi, et al., 2012). Therefore, it could be argued that even very effective theoretical education in the academic context can be of little use when the student encounters the complexities of the clinical situation (McCaugherty, 1991; Nabolsi et al., 2012; Smith et al., 2007).

The literature showed several suggestions to close the gap between theory and practice in nursing education. For instance, it was suggested that learning be put in a context that makes it clearer to be understood by students (Stockhausen, 2005). Giving real examples during lectures may reduce the feelings of mystery students report as they implement their theoretical learning in real situations. Several authors have warned of the danger of keeping students away from the clinical environment for a long time (Elkan \& Robinson, 1993; Fulbrook et al., 2000). Chesser-Smyth (2005) explained that student nurses become more satisfied when gaining clinical skills. Students need these skills to be able to provide holistic care.

Several studies explained the importance of supporting student nurses, especially in the clinical area (Brown et al., 2008; Jokelainen, 2011). This support should begin from the school level. However, students particularly need more support in the clinical 
area (Landers, 2000; Nabolsi et al. 2012). Supporting student nurses may take several aspects. Landers (2000) stated that the number of nursing teachers in the clinical area should be increased. They indicated that nursing teachers should spend more time in the clinical area to ensure student learning, linking theory to practice. Providing support also includes direct application of the theory learned in the classroom to practice (Landers, 2000). More importantly, nursing teachers are required to adopt an advocacy role to enable the student to be understood and empowered (McCleland \& Williams, 2002).

The traditional way of learning should be always assessed and evaluated. New modifications and creative strategies are always needed to improve the quality of learning. For instance, many universities in the UK have adopted the Project 2000 in the educational process for undergraduate student nurses (Landers, 2000) This project aims to modify the teaching and learning methodologies, with greater emphasis on experiential and self-direct learning (Parker \& Carlisle, 1996). After ten years of implementing this project, conclusions drawn by the United Kingdom Central Council's (UKCC) Commission on Nurse and Midwifery Education (UKCC, 1999) suggested that Project 2000 reforms have been very effective in improving nursing education and nursing students' readiness for the transition to clinical practice.

Several authors have stressed the importance of cooperation between education and practice sectors (Landers, 2000; McKenna \& Wellard, 2009). The role of both preceptor and mentor were suggested by some authors to reduce the gap between theory and practice (Landers, 2000; Sharif \& Masoumi, 2005). Both the mentor and preceptor are clinical staff with supervision experience. The job of the mentor is mainly to support the students in the clinical area, while the preceptor works directly with the students (Landers, 2000). Similarly, a position of lecturer-practitioner was suggested (Fairbrother \& Ford, 1998; Landers, 2000). Lecturerpractitioners should have both clinical and teaching experiences, and should work with students in the classroom as well as the clinical area.

Nursing education in Jordan is among the best in Middle East (Zahran, 2012). The quality of Jordanian nurses and the reputation of nursing education in Jordan form a challenge to the nursing schools and the stakeholders to maintain this high level of nursing education, especially when adopting new and uncertain approaches. It is known that most of the experienced nurses leave the Jordanian hospitals to work outside Jordan (AbuAlRub, 2010), generally for economistic reasons. This keeps the door ever open for newly graduated nurses to take the positions of these nurses within Jordan. Therefore, more responsibilities are placed on novice nurses than they would face in developed countries as newly qualified professional, and hospitals will depend on them and their expertise to a much greater extent. Therefore, it is highly important for graduate nurses to be ready to work in the hospital field. This could be achieved by putting more effort on the clinical training of the nursing students as well as the effort put on the theoretical part. This study explores challenges faced in nursing education in Jordan with particular reference to the theory-practice gap in nursing education. The aim of this study was to identify suggestions and interventions to explore the students' perceptions about theory-practice gap in nursing education.

\section{Methods}

\subsection{Study design}

A few studies on the theory-practice gap in Jordan were conducted. Two studies (Nabolsi et al., 2012; Safadi et al., 2011) were reviewed in this field, but none of them directly searched for the reasons for the existence of this gap or suggestions to close it Therefore, qualitative research is preferred for emerging and new areas of research as it identifies phenomena that can later be investigated using other approaches. Qualitative researchers believe that reality is understood through people sharing experiences and in- teractions with others (Bryman, 2012). Detailed data is gathered through open-ended questions that provide direct quotations revealing insights into the world constructed by research participants. Rather than being passive, objective observers, qualitative interviewers are integral parts of the research context (Weber, 2004). Therefore, qualitative research seems to be effective when there is a need for more understanding of social phenomena such as the theory-practice gap in nursing education. Individual, semistructured, in-depth interview was selected as the method of data collection. Patton (2002) describes the semi-structured interview as a series of topics or broad interview questions in which the researcher is free to explore and probe the interviewee.

Two pilot interviews with nursing students were conducted before starting the process of data collection. Conducting these interviews before the actual interviews increased the interviewers' ability to interact with the interviewees. The interviewers also felt more confident to start the actual interviews, and they attained better ability to stimulate the interviewees to express their accounts.

At the beginning of the interviews, each participant received an explanation about the purpose of the study and the method of data collection. The authors prepared in advance a series of open-ended questions to be asked based on a literature review in this field, such as could you tell me about your experience as a student nurse What was your perception when you went to the clinical area for the first time? What kind of support did you receive in clinical training? And do you have any suggestions to decrease the theorypractice gap in nursing education? The questions were inspired by previous studies (particularly unexplained issues in these articles) and the experiences of the authors. The emergent characteristics of the qualitative design (Polit \& Beck, 2013) formed the third source for the interview schedule in the current study. In addition to these questions, the door was kept open for any new emergent questions. Interview duration ranged from 40 to 60 minutes. All interviews were audio recorded.

\subsection{Setting and sample}

The sample was derived from a population of one nursing school of a private university in Jordan. A purposive sample of 30 nursing students was recruited. Approximately two-thirds of the sample were female. The recruiting for students continued until the point of data saturation, when no new data emerges and the responses become repetitive (Mason, 2002). The population targeted was students attending the Applied Science Private University in Amman who took clinical courses. The selected students had attended at least two clinical courses to ensure they would have a full understanding of the topic and enough clinical practice to compare to what is learned from theory. We excluded bridging students because most of these students have had working experience in the hospitals and it would be hard for them to relate to the theory-practice gap. The students' ages were between 19 and 24 years old, with a mean of 20.6 years.

\subsection{Sample recruitment}

The purpose of this study was to obtain rich and deep information about the theory-practice gap in nursing education in Jordan. To achieve this goal, the participants could talk freely without pressure about this subject. This was expected to be achieved by recruiting three postgraduate students to conduct the interviews, all of whom received good training and preparation to do the interviews. Student interviewers were expected to decrease the pressure on the study participants, especially when critiquing teachers or the educational plan in their school.

To recruit the study sample, face-to-face invitation was extended by the volunteer students to most of the students who met the inclusion criteria. A brief explanation about the study objectives and the data collection procedure was provided. Invitations were also done by preparing a poster displayed on all advertisement boards in the school. In both invitation methods, the contact details of the 
study authors were provided. All students who met the inclusion criteria and agreed to take part of the current study were invited to be interviewed. Each participant was given a consent form to be signed at the beginning of the interview.

\subsection{Ethical issues}

Ethical approval was obtained from the school of nursing in the Applied Science Private University. Each participant had the righ to decide voluntarily whether to participate in a study, without risking any penalty or prejudicial treatment and to terminate their participation at any time. All participants were informed that their responses would be treated confidentially and anonymously. Each participant was asked to fill in a consent form before each interview. This form was accompanied by an information sheet. All data was kept in a locked file and access to identifying information was restricted to the study authors. Each participant was asked to sign a consent form and was told that they could change their minds during the research and withdraw from the study of withhold information at any time. The names and identity of the participants should not be revealed as a result of data collection, analysis, and reporting in the research study (Gerrish \& Lacey, 2010). Names used in this paper are pseudonyms.

\subsection{Data analysis}

Braun and Clarke's (2006) technique of thematic analysis was utilized to analyse our data. Interviews were transcribed verbatim by one of the authors. The first phase of data analysis was familiarization with the data. This was achieved by active listening to the interviews and self-transcription by one of the authors. The second step includes generating initial codes. All transcripts were entered into the NVivo software. All interviews were carefully read and examined line-by-line. We always asked ourselves "what did this person want me to understand by saying this?" The third phase includes searching for themes.

In the early stages, the process of coding was not organized. All respondents' sentences, phrases and texts were assigned one or more codes. These codes were transferred into the free nodes in NVivo. With the progress of time, and with the increase in the number of codes, more analytical codes were developed. As the analysis developed the codes were grouped together in a 'tree' structure (tree nodes in NVivo software), to facilitate the process of analysis, developing themes and theory building. The fourth phase includes reviewing the themes. Once all the data had been entered, the codes were refined. The aim was to reduce their number, eliminate duplication and permit the development of more sophisticated analytical categories. As this process continued, new links between codes became apparent. The fifth phase includes defining and naming the themes. At this step, five themes were assigned. The final phase of data analysis includes producing the report. This phase formed the starting point of writing our results section.

\subsection{Research rigour}

Angen (2000) showed that the credibility of research depends on the skill and competence of the researcher. Therefore, good training and preparing for the researcher should be done before conducting a qualitative study (Sandelowski, 2002). For the current study, all the interviewers received good training about the techniques of conducting semi-structured interviews. Two pilot interviews were also done before starting the process of data collection. Writing field notes and using a personal journal during data collection were expected to improve the credibility of the study (Tuckett, 2005). Recording field notes were used in this study by using a specific journal to write down notes and comments about each interview. Additionally, all interviews were tape-recorded. Credibility is increased as a result of selecting purposive sampling (Tuckett, 2005). This also contributes in facilitating the transferability (Lincoln \& Guba, 1985) because purposive sampling opens the way for producing the widest possible range of information. Considering and not ignoring negative cases contributes in promoting the credibility and dependability of a qualitative study (Tuckett, 2005). Not only, the similar opinions of the majority were assigned, but also those respondents deemed outside the general were indicated.

\section{Results}

The findings of the current study were expected to shed some light on the nursing education in Jordan. Unsurprisingly, most of the students in the current study indicated that there is a huge gap between the classroom theoretical contents and what they found in the complex clinical environment. This study was particularly focused on identifying the suggestions and intervention to decrease the theory-practice gaps in nursing education. The statements of students were collected and built into four major themes: open channels between theory and practice teachers; students need to be supported more; increasing the competency of clinical instructors; and preparing and improving the laboratories.

\subsection{Open channels between theory and practice teachers}

The students showed the importance of opening channels of communication between the teachers in the classroom and the instructors in the clinical settings. By opening these channels of communication, the theory teachers could coordinate with the clinical instructors to focus on specific subjects in the clinical setting. For example, after attending a lecture about diabetes mellitus in the classroom, the clinical instructor would ask the students to focus on diabetic patients, and they try to link the information that was taken in theory with the clinical cases. This process could also be implemented visa-versa by discussing those viewed in the clinical training in the classroom.

Well, I think that there should be communication between our teachers in the school with the instructors in the practice. They both should have an idea about what is going on in the other part. (Student 12)

More interestingly, more than two-thirds of students suggested that theory teachers and clinical instructors should be same as people. This was thought to strengthen the link between the material given in theory, and the material covered in practice. According to this notion, the teacher would present a lecture about a subject in the classroom, and the next-day go to the clinical area and explain the same material on real cases. This would require greater flexibility in the educational process, but would obviously produce more consistent educational delivery. Depending on the available cases in the clinical area, the nursing teachers could modify their lecture timetables. This would produce harmony between the content of education in the classroom and the material given in the practice area.

I suggest if they were the same person it would be better because they will organize between topics given in theory and what is taken in practice in clinical area, and they will help us to understand what we learn. (Student 25).

\subsection{Students need to be supported more}

More than half of the students thought that they did not receive good support in the clinical area. Many of them expressed the importance of providing this support, especially in the very early practical courses such as the medical-surgical clinical course. Some of these students said that they were left alone on their first day in the hospital. Some students felt that the clinical instructors were not qualified enough to recognize their needs at that time. The instructors did not know how to deal with students and how to be supportive for them. Some explained that their instructors were busy completing some routine managerial issues, decreasing the time left for students. 
I remembered the first days in my training in medical-surgical. The instructor was very busy in many managerial businesses. Our instructor did not support us. I believe that they did not recognize our needs at that time. It was not easy to be left alone while you were in need for any help and support. (Students 18)

The students explained the importance of being supported during their training. Some students indicated that this support should be started from the school before going to the clinical area. This was expected to be achieved by classroom instructions and general advices about the clinical settings. While a few students stated that they received explanation about what they will see in the clinical area, many of them thought that this explanation was not enough. These students explained that the training in the classrooms and the laboratories on models was completely different from the real complex clinical environment.

Yes, we received training in the laboratory in the first year. However, this was not enough. To be honest, the reality is completely different ... I think we should be prepared more. We need more support. (Student 22)

Some students complained about the method of communication adopted by their clinical instructors. They explained that every one of them is a unique person with special personal characteristics. I was suggested that the instructors should consider the differences between students. For example, some students did not have the courage to talk with patients, and some others needed more time to adapt to the new environment and the staff in the clinical setting. These students were blamed inappropriately in front of their colleagues and sometimes in front of the staff or the patients in the department. Therefore, many of the students suggested the need for improving the instructors' communication skills.

I just think the clinical instructors should be more open-minded and understanding, not as narrow-minded as they sometimes are. (Students 5)

Well, they do not consider the differences between us ... We are not the same. (Student 1)

\subsection{Increasing the competency of clinical instructors}

In most Jordanian nursing schools, there is no condition to have clinical nursing experience to work as a nursing teacher or clinical instructor. Some nursing teachers and clinical instructors have no experience in hospitals or clinical settings, depending purely on books and their education to teach nursing students. Students explained that clinical instructors focus only on grades and marks and some of them felt that paperwork and assignments are the main interests of most clinical instructors. Interestingly, some of the students felt that there were no differences between the material given in theory and their clinical training.

You feel sometimes that they do not know what is going on. I think that some of them had never been in a hospital before. I believe that having good clinical experience will facilitate their job as clinical instructors. (Student 19)

Most of the students appreciated the importance of having clinical experience to be a successful instructor. Some students talked, frankly, about real examples from their experiences. They found that the instructors with previous experiences in the clinical settings were more supportive for them. These instructors also facilitated their learning because they knew exactly what to focus on and how to break the ice between the students and the clinical environment.

I remembered while I was in the medical-surgical clinical module. We had two instructors ... they were skillful, and they had good knowledge. This helped us so much . They also, had good relationships with the staff in the wards and they were talking easily with patients. They were like the role model for us. (Student 14).

Most of the students indicated that nursing is different from other disciplines, thus the educational approach in the discipline should be different. It was not acceptable to several students that nursing teachers explained diseases in purely scientific and abstract ways without giving real examples. The students suggested presenting real-life case studies in classroom lectures and then discussing these cases with consideration of all issues that may influence them.

Instead of providing a lecture about hypertension and giving detailed information about this subject, the lecturer can present really hypertensive cases that were taken from the hospitals. We can see how this disease influenced on patients' functional health patterns. (Student 23)

Using more audiovisual materials in the theoretical lectures was expected to help nursing students to understand the complexity of several health conditions. For instance, nursing teachers may use a real or animation movie to explain how to do cardiac catheterization. One student said that she could not understand the possibility of inserting a catheter tube into the coronary arteries and putting in a stent. Explaining these procedures in a theoretical lecture was appropriate and easy for the views of the nursing teachers. However, according to this student, most students in that lecture had no idea about the reality of cardiac catheterization and these procedures. Interestingly, this student understood this procedure by going to the Internet and watching a film about this procedure.

For our teacher, everything was easy ... but for us, the situation was completely different. We used our imagination to understand. I remember that I went to the internet to understand how somebody could insert a catheter through femoral artery to reach the coronary artery and put stent there. (Student 11)

\subsection{Preparing and improving the laboratories}

Most of the students appreciated the roles of their teachers and clinical instructors in teaching them about the reality of the nursing profession. More importantly, the students indicated that they spent two of the fourteen weeks specified for each practical module in the laboratory. However, several students explained that the laboratories in their school and those in most of the Jordanian nursing schools were not equipped to prepare nursing students for the real complex clinical environment. The students expressed the need for better and more advanced equipment in their labs. One female student talked about the physical examination course, in particular, and said that it was hard for her to learn all the abnormalities and memorize them when she did not see them. She also said that she thought it was a waste of time for them to practice on models ('dolls') when they would not learn normal things.

I just felt that our practice for theory is sometimes useless; like the physical exams, our dolls and equipment need some updating. (Student 7)

Some students in the current study presented more specific suggestions to improve the labs in their school. These students saw specific programs on television about simulation labs. Training in these labs was expected to close the gap between theory and practice in nursing education. One student, for example, had been in a nursing school in the US while she was visiting her sister. She explained:

I saw these amazing labs that were set up in the United States for nursing students. I wish we had them here to facilitate leaning for us. The dolls would talk and make noises and you actually feel like you were dealing with a real patient. (Student 5).

\section{Discussion}

The findings of the current study could be transferable to other regions with similar conditions. Reviewing the body of literature shows that this subject was examined in several studies (Gillespie \& McFetridge, 2006; Landers, 2000; Sharif \& Masoumi, 2005). The current study added more information about this subject and raised some suggestions and interventions in a systematic way to decrease the gaps between theory and practice in nursing education. These suggestions were produced from nursing students who talked about their experiences. These students are the most important component in the nursing education process. Therefore, 
their reflections and opinions are important to develop the process of nursing education.

Most of the students in the current study showed the need for more communication and coordination between theory teachers and clinical instructors. This was also raised in the literature (Jokelainen et al., 2011; McBrien, 2006; Smith et al., 2007). Myall, Levett-Jones \& Lathlean (2008) indicated that the cooperation between theory and practice is not adequate, due to the difficulty of transferring theoretical knowledge into a clinically complex area (Chan, 2005; Nabolsi et al., 2012; Smith et al., 2007). This may cause many students to be shocked when examining their ideal expectations and knowledge with real practice settings (Gallagher, 2004; Scully, 2011), exacerbating the theory-practice gap in nursing education. Therefore, the findings of the current study and results of several articles (Chapple \& Aston, 2004; Gallagher, 2004; Nabolsi et al., 2012) suggest opening more channels of communication between theory teachers and clinical instructors. The findings of the present study are in agreement with the findings of several studies that nursing students need to be supported in clinical training (Brown et al., 2008; Clare \& Loon, 2003; Nabolsi et al., 2012; Sharif \& Masoumi 2005). This may be due to several factors such as lack of clinical experience, unfamiliarity with place, complex clinical cases, fear of doing something wrong and the worry of being evaluated by their teachers (Beck \& Srivastava, 1991; Sharif \& Masoumi, 2005). Therefore, clinical instructors and theory teachers should increase students' confidence (Grundy, 1993) by creating a nurturing and supportive environment (Calpin-Davies, 2003). Increasing the knowledge and skills of nursing students was expected to decrease their level of stress (Bradbury-Jones, Irvine, \& Sambrook, 2010). Other suggestions such as providing regular feedback regarding students' performance and listening to students reflections were also raised in literature (Happell, 2009; Nabolsi et al. 2012).

Interestingly, Nabolsi et al. (2012) qualitatively examined the experience of Jordanian nursing students in their clinical training. They interviewed 30 nursing students at the undergraduate level. It was reported that there was a deficiency of supporting students in the clinical area. The current study was also conducted in Jordan and produced similar findings. This may explain the reactions of many students and their focusing on the importance of providing more support from nursing teachers and instructors for students, especially in their initial period of training. Providing this support was expected to improve students' satisfaction and to increase their enthusiasm and retention in the profession (Pearcey \& Elliott, 2004; Pellatt, 2006).

A very important point was raised by several students regarding the qualifications of clinical instructors. Many of the students explained that their instructors were qualified, and they had good certificates in nursing, but some thought that clinical instructors were not able to communicate with them, and they did not understand their needs. This might have resulted from the complexity of clinical training, which consists of integrating cognitive affective and psychomotor skills (Nabolsi et al., 2012; Reilley \& Oerman, 1992). It was indicated that competent instructors are able to ease the process of education in clinical settings, and they have effective communication skills (Stevenson, Randle, \& Grayling, 2006). Therefore, clinical instructors should meet specific criteria to do their job perfectly. For example, clinical instructors in the UK should achieve national standards such as requirements for training, annual updating, local registering, review and maintenance of qualifications (Nursing \& Midwifery Council (NMC), 2008). However, this is not the case in all countries. In Jordan, for example, there are no national standards for clinical instructors. Many universities do not have a condition for their instructors to have clinical experience. Many of these instructors had never been in training about how to deal with nursing students. This may decrease their ability to effectively supervise and guide nursing students in the clinical settings.

Most of the students did not ignore the role of lab training in preparing them for the real clinical training. However, most of them thought that this was not enough. Some of them heard about the newly developed simulation labs wherein students feel that they are in real clinical settings. Training on dolls without responses was unrealistically easy for students; they explained that they were shocked when they encountered real (i.e. living, responsive) patients in real settings. For example, taking a blood sample from an inanimate doll is much easier than taking a sample from a living patient, suffering and in pain. McCallum (2007) showed the role of learning through simulation in developing nursing students' clinical experience and in preparing them to behave in real clinical settings. Training students through simulation results in some advantages, such as providing planned training, allowing for crisis intervention and teaching team work, and giving more chances for discussion and reflection on training, all without posing any danger to real patients (McFetrich, 2006).

\section{Limitations}

It is possible that the negative attitudes that were raised by most of the students were unique to particular sets of circumstances present in the included university only, at that moment in time. What can be stated with more certainty is that the findings may not be generalised to contexts outside of this university. The applicability of our findings to other populations is limited, because our respondents were a relatively homogeneous group. It has been shown that all respondents are Jordanian students from one private university. The findings of this study may be transferable when we deal with people with similar conditions. The population of this study was limited to nursing students. Including other key people such as nursing teachers, clinical instructors and nurses from the clinical settings may add more strength to the findings.

\section{Conclusion}

This study described students' experiences in the theory and clinical settings. The students suggested some solutions to decrease the gaps between theory and practice. One of the most insightful suggestions was that the teacher in the theory and practice should be the same person, to improve the link between what was learned in theory and practice. This could be achieved when the students go to the clinical setting, and the instructors have to show a case that is related to what they took in the theory. This would entail a fundamental rethink of pedagogy in Jordanian nursing education.

The qualitative design used in this study provided deep and rich data about the theory-practice gaps in nursing education in Jordan. The students' experiences and the possible interventions for these gaps were deeply discussed. Additionally, to our knowledge this study is the first to examine this subject in Jordan. Therefore, the information raised in this study could be useful for undergraduate students, nursing schools, nursing teachers and other healthcare stakeholders in Jordan. The findings of this study could be also transferred to be useful to other countries with similar conditions.

\section{Acknowledgments}

The authors are grateful to the Applied Science Private University, Amman, Jordan, for the partial financial support granted to this research project.

\section{References}

[1] AbuAlRub, R. F. (2010). Work and non-work social support and intent to stay at work among Jordanian hospital nurses. International Nursing Review, 57(2), 195-201. http://dx.doi.org/10.1111/j.14667657.2009.00768.x.

[2] Allan, H. T., Smith, P., \& O’Driscoll, M. (2011). Experiences of supernumerary status and the hidden curriculum in nursing: a new twist in the theory-practice gap? Journal of Clinical Nursing, 20(5-6), 847-855. http://dx.doi.org/10.1111/j.1365-2702.2010.03570.x. 
[3] Angen, M. J. (2000). Evaluating Interpretive Inquiry: Reviewing the Validity Debate and Opening the Dialogue. Qual Health Res, 10(3) 378-395. http://dx.doi.org/10.1177/104973230001000308.

[4] Beck, D., \& Srivastava, R. (1991). Perceived level and source of stress in baccalaureate nursing students. Journal of Nursing Education, 30(3), 127 - 132.

[5] Bradbury-Jones, C., Irvine, F., \& Sambrook, S. (2010). Empowermen of nursing students in clinical practice: spheres of influence. Journal of Advanced Nursing, 66(9), 2061-2070. http://dx.doi.org/10.1111/j.1365-2648.2010.05351.x.

[6] Braun, V., \& And Clarke, V. (2006). Using thematic analysis in psychology. Qualitative Research in Psychology, 3 (2), 77-101. http://dx.doi.org/10.1191/1478088706qp063oa.

[7] Brown, J., Nolan, M., Davies, S., Nolan, J., \& Keady, J. (2008). Transforming students' views of gerontological nursing: Realising the potential of 'enriched' environments of learning and care: A multimethod longitudinal study. International Journal of Nursing Studies, 45(8), 1214-1232.

[8] Bryman, A. (2012). Social Reasearch Mehtods (4th edition). NewYork: Oxford University Press

[9] Budgen, C., \& Gamroth, L. (2008). An overview of practice education models. Nurse Education Today, 28(3), 273-283. http://dx.doi.org/10.1016/j.nedt.2007.05.005.

[10] Calpin-Davies, P. J. (2003). Management and leadership: a dual role in nursing education. Nurse Education Today, 23(1), 3-10. http://dx.doi.org/10.1016/S0260-6917(02)00157-0.

[11]Chan, D. S. (2005). Nursing students' perceptions of hospital learning environments-an Australian perspective. International Journal of Nursing Education Scholarship, 1(1).

[12]Chan, Z. (2013). A systematic review of creative thinking/creativity in nursing education. Nurse Education Today, 33(11), 1382-1387. http://dx.doi.org/10.1016/j.nedt.2012.09.005.

[13]Chapple, M., \& Aston, E. S. (2004). Practice learning teams: a partnership approach to supporting students' clinical learning. Nurse Education in Practice, 4(2), 143-149. http://dx.doi.org/10.1016/S1471-5953(03)00038-6.

[14]Chesser-Smyth, P. A. (2005). The lived experiences of general student nurses on their first clinical placement: A phenomenological study. Nurse Education in Practice, 5(6), 320-327. http://dx.doi.org/10.1016/j.nepr.2005.04.001.

[15]Clare, J., \& Loon, A. v. (2003). Best practice principles for the transition from student to registered nurse. Collegian, 10(4), 25-31. http://dx.doi.org/10.1016/S1322-7696(08)60073-6.

[16]Dale, A. E. (1994). The theory-theory gap: the challenge for nurse teachers. Journal of Advanced Nursing, 20(3), 521-524. http://dx.doi.org/10.1111/j.1365-2648.1994.tb02390.x.

[17]Elkan, R., \& Robinson, J. (1993). Project 2000: the gap between theory and practice. Nurse Education Today, 13(4), 295-298. http://dx.doi.org/10.1016/0260-6917(93)90056-8.

[18] Fairbrother, P., \& Ford, S. (1998). Lecturer practitioners: a literature review. Journal of Advanced Nursing, 27(2), 274-279. http://dx.doi.org/10.1046/j.1365-2648.1998.00525.x.

[19]Fitzpatrick, J. M., While, A. E., \& Roberts, J. D. (1996). Key influences on the professional socialisation and practice of students undertaking different preregistration nurse education programmes in the United Kingdom. International Journal of Nursing Studies, 33(5), 506-518. http://dx.doi.org/10.1016/0020-7489(96)00003-X.

[20]Fulbrook, P., Rolfe, G., Albarran, J., \& Boxall, F. (2000). Fit for practice: Project 2000 student nurses' views on how well the curriculum prepares them for clinical practice. Nurse Education Today, 20(5), 350-357. http://dx.doi.org/10.1054/nedt.2000.0479.

[21]Gallagher, P. (2004). How the metaphor of a gap between theory and practice has influenced nursing education. Nurse Education Today, 24(4), 263-268. http://dx.doi.org/10.1016/j.nedt.2004.01.006.

[22]Gerrish, K., \& Lacey, A. (2010). The research process in nursing. John Wiley \& Sons.

[23]Gillespie, M., \& McFetridge, B. (2006). Nurse education - the role of the nurse teacher. Journal of Clinical Nursing, 15(5), 639-644. http://dx.doi.org/10.1111/j.1365-2702.2006.01344.x.

[24] Grundy, S. (1993). The confidence scale. Nurse Educator, 18(1), 6 - 9. http://dx.doi.org/10.1097/00006223-199301000-00004.

[25] Happell, B. (2009). A Model of PRECEPTORSHIP in Nursing: Reflecting the Complex Functions of the Role. [doi: 10.1043/15365026-30.6.372]. Nursing Education Perspectives, 30(6), 372-376.

[26]Jokelainen, M., Turunen, H., Tossavainen, K., Jamookeeah, D., \& Coco, K. (2011). A systematic review of mentoring nursing students in clinical placements. Journal of Clinical Nursing, 20(19-20), 28542867. http://dx.doi.org/10.1111/j.1365-2702.2010.03571.x.
[27]Landers, M. G. (2000). The theory-practice gap in nursing: the role of the nurse teacher. Journal of Advanced Nursing, 32(6), 1550-1556. http://dx.doi.org/10.1046/j.1365-2648.2000.01605.x.

[28] Lincoln, Y., \& Guba, E. (1985). Naturalistic inquiry. Beverly Hills: CA: Sage.

[29] Mason, J. (2002). Qualitative researching. London: Sage Publication.

[30]McBrien, B. (2006). Clinical teaching and support for learners in the practice environment. British Journal of Nursing, 15(12), 672-677. http://dx.doi.org/10.12968/bjon.2006.15.12.21401.

[31] McCallum, J. (2007). The debate in favour of using simulation education in pre-registration adult nursing. Nurse Education Today, 27(8), 825-831. http://dx.doi.org/10.1016/j.nedt.2006.10.014.

[32] McCaugherty, D. (1991). The theory-practice gap in nurse education: its causes and possible solutions. Findings from an action research study. Journal of Advanced Nursing, 16(9), 1055-1061. http://dx.doi.org/10.1111/j.1365-2648.1991.tb03366.x.

[33] McCleland, A., \& Williams, A. (2002). An emancipatory praxis study of nursing students on clinical practicum in New Zealand: Pushed to the peripheries. [doi: 10.5172/conu.12.2.185]. Contemporary Nurse, 12(2), 185-193. http://dx.doi.org/10.5172/conu.12.2.185.

[34] McFetrich, J. (2006). A structured literature review on the use of high fidelity patient simulators for teaching in emergency medicine. Emergency Medicine Journal, 23(7), 509-511. http://dx.doi.org/10.1136/emj.2005.030544.

[35] McKenna, L., \& Wellard, S. (2009). Mothering: an unacknowledged aspect of undergraduate clinical teachers' work in nursing. Advances in Health Sciences Education, 14(2), 275-285. http://dx.doi.org/10.1007/s10459-008-9109-3.

[36] Myall, M., Levett-Jones, T., \& Lathlean, J. (2008). Mentorship in contemporary practice: the experiences of nursing students and practice mentors. Journal of Clinical Nursing, 17(14), 1834-1842. http://dx.doi.org/10.1111/j.1365-2702.2007.02233.x.

[37]Nabolsi, M., Zumot, A., Wardam, L., \& Abu-Moghli, F. (2012). The Experience of Jordanian Nursing Students in their Clinical Practice. Procedia - Social and Behavioral Sciences, 46(0), 5849-5857. http://dx.doi.org/10.1016/j.sbspro.2012.06.527.

[38] Nursing \& Midwifery Council (NMC). (2008). Standards to support learning and assessment in practice. NMC Standards for Mentors, Practice Teachers and Teachers: NMC, London.

[39]Parker, T. J., \& Carlisle, C. (1996). Project 2000 students' perceptions of their training. Journal of Advanced Nursing, 24(4), 771-778. http://dx.doi.org/10.1046/j.1365-2648.1996.25416.x.

[40]Patton M. (2002). Qualitative research and evaluation methods. Thousand Oaks: CA: Sage Publications, Inc.

[41]Pearcey, P. A., \& Elliott, B. E. (2004). Student impressions of clinical nursing. Nurse Education Today, 24(5), 382-387. http://dx.doi.org/10.1016/j.nedt.2004.03.007.

[42]Pellatt, G. C. (2006). The role of mentors in supporting preregistration nursing students. [doi: 10.12968/bjon.2006.15.6.20683]. British Journal of Nursing, 15(6), 336-340. http://dx.doi.org/10.12968/bjon.2006.15.6.20683.

[43]Polit, D., \& Beck, C. (2013). Essentials of Nursing Research: Lippincott Williams \& Wilkins.

[44]Reilley, D., \& Oermann, M. (1992). Clinical Teaching in Nursing Education: New York: National League of Nursing.

[45] Safadi, R. R., Saleh, M. Y. N., Nassar, O. S., Amre, H. M., \& Froelicher, E. S. (2011). Nursing students' perceptions of nursing: a descriptive study of four cohorts. International Nursing Review, 58(4), 420-427. http://dx.doi.org/10.1111/j.1466-7657.2011.00897.x.

[46]Sandelowski, M. (2002). Reembodying Qualitative Inquiry. Qual Health Res, 12(1), 104-115. http://dx.doi.org/10.1177/1049732302012001008.

[47] Scully, N. J. (2011). The theory-practice gap and skill acquisition: An issue for nursing education. Collegian, 18(2), 93-98. http://dx.doi.org/10.1016/j.colegn.2010.04.002.

[48]Sharif, F., \& Masoumi, S. (2005). A qualitative study of nursing student experiences of clinical practice. BMC Nursing, 4(1), 6. http://dx.doi.org/10.1186/1472-6955-4-6.

[49] Smith, K., Clegg, S., Lawrence, E., \& Todd, M. J. (2007). The challenges of reflection: students learning from work placements. [doi: 10.1080/14703290701241042]. Innovations in Education and Teaching International, 44(2), 131-141. http://dx.doi.org/10.1080/14703290701241042.

[50] Stevenson, K., Randle, J., \& Grayling, I. (2006). Inter-group conflict in health care: UK students' experiences of bullying and the need for organisational solutions. Online journal of issues in nursing, 11(2), 66.

[51] Stockhausen, L. J. (2005). Learning to become a nurse: Students reflections on their clinical experiences. Australian Journal of Advanced Nursing, 22(3), 8-14. 
[52]Tuckett A. (2005). Part II. Rigour in qualitative research: complexities and solutions. Nurse Researcher, 13(1), 29-42. http://dx.doi.org/10.7748/nr2005.07.13.1.29.c5998.

[53] United Kingdom Central Council for Nursing Midwifery and Health Visiting (1999) Fitness for Practice: the UKCC Commission for Nursing and Midwifery Education (Chair: Sir Leonard Peach). UKCC, $\mathrm{L}$.

[54]Upton, D. J. (1999). How can we achieve evidence-based practice if we have a theory-practice gap in nursing today? Journal of Advanced Nursing, 29(3), 549-555. $\quad$ http://dx.doi.org/10.1046/j.13652648.1999.00922.x.

[55] Weber, R. (2004). The rhetoric of positivism versus interpretivism: A personal View. MIS Quarterly, 28(1), iii-xii.

[56]Zahran, Z. (2012). Nurse education in Jordan: history and development. International Nursing Review, 59(3), 380-386. http://dx.doi.org/10.1111/j.1466-7657.2011.00947.x. 